J. Lake Sci.(湖泊科学), 2017, 29(2):317-325

DOI 10. 18307/2017. 0207

(C) 2017 by Journal of Lake Sciences

\title{
千岛湖流域下游工业污染的行业组成结构与优化管理策略”
}

\author{
鲁文艳 ${ }^{1,2}$, 李恒鹏 ${ }^{2 * *}$, 吴志㝵 ${ }^{3}$, 于兴修 ${ }^{1}$, 陈东强 ${ }^{2}$ \\ ( 1 : 湖北大学资源环境学院, 武汉 430062) \\ (2: 中国科学院南京地理与湖泊研究所中国科学院流域地理学重点实验室,南京 210008) \\ (3: 淳安县环境保护局, 杭州 311700)
}

\begin{abstract}
摘 要: 工业污染作为重要的污染源, 了解工业污染的行业结构组成以及企业污染状况对污染减排以及水环境保护具有 重要作用. 2015 年国家出台的 “水污染防治行动计划”明确提出,要通过产业结构调整狠抓工业污染减排. 千岛湖作为国 家级战略水源地, 被列人国家良好湖库保护战略首批试点, 评价千岛湖地区的工业污染行业结构对制定工业行业调整方 案和企业管理制度具有重要的意义. 选取千岛湖流域下游行政区淳安县为研究区, 采用不同工业行业的 180 家主要排污 企业, 在工业行业污染结构分析的基础上, 选取经济贡献、污染产生强度和治理水平三方面的关键指标, 运用聚类分析法 对行业和企业进行综合类型划分. 结果表明: 在涉及 $\mathrm{COD}_{\mathrm{Mn}}$ 排放的 19 类工业行业中纺织业、饮料制造业和金属制品业为 支柱产业, 饮料制造业和纺织业为主要污染行业, 现状工业行业结构存在一定的结构性污染问题; 结合不同行业和企业 的经济贡献、污染物产生强度以及治理效率的综合分析, 将行业划分为 6 类, 并根据各类型特点提出重点发展、鼓励发展、 限制发展的行业优化策略; 企业划分为 4 类, 并提出重点支持、鼓励、限制发展以及逐渐关停的企业监管策略. 通过对工 业行业和企业的分类与评价可为其它地区提供借鉴, 同时有利于为 “水污染防治行动计划” 的落实提供技术方法指导.
\end{abstract}

关键词: 行业污染;企业;聚类分析;优化策略;千岛湖流域

\section{Industry pollution structure and the optimal management strategy in lower reaches of Lake Qiandao Basin}

\author{
LU Wenyan ${ }^{1,2}$, LI Hengpeng ${ }^{2 * *}$, WU Zhixu ${ }^{3}$, YU Xingxiu ${ }^{1} \&$ CHEN Dongqiang ${ }^{2}$ \\ (1: College of Resource and Environment, Hubei University, Wuhan 430062, P.R.China) \\ (2: State Key Laboratory of Basin Geography, Nanjing Institute of Geography and Limnology, Chinese Academy of Sciences, \\ Nanjing 210008, P.R. China) \\ (3: Chunan Environmental Protection Bureau, Hangzhou 311700, P.R. China)
}

\begin{abstract}
Industry pollution is an important pollution source. It is important to understand the effects of pollution structure and enterprise pollution conditions on water environment. The “water pollution prevention action planning” launched in 2015 clearly put forward that industrial pollution emissions must be reduced through adjusting the industrial structure vigorously. As a national-level drinking water source, the Lake Qiandao was taken as one of pilot areas to pursue the good water quality of lakes and reservoirs. It is of important significance to evaluate the industrial pollution composition of Lake Qiandao Basin and develop industry adjustment scheme and enterprise management system. This study selected 180 enterprises which have large $\mathrm{COD}_{\mathrm{Mn}}$ emissions in lower reaches of Lake Qiandao Basin. Based on the analysis of the pollution structure of the industrial sector, taking the indexes of economic contribution, pollution intensity, and level of governance as key indicators, industries and enterprises were classified using the cluster analysis. The results indicate that the textile industry, beverage manufacturing industry and metal products industry were the pillar industries, and the beverage manufacturing industry and textile industry were the major polluting industries in relation to the $\mathrm{COD}_{\mathrm{Mn}}$ emissions of 19 types of industries. It is apparent that the present industry structure has a big structural pollution problem.
\end{abstract}

* 国家自然科学基金项目 (41271500)、中国科学院重点部署项目(KZZD-EW-10-04)、中国科学院南京地理与湖泊研 究所“一三五”重点布署项目 (NIGLAS2012135005) 和浙江省淳安县环境保护局科研项目联合资助.2016-02-26 收稿;2016-06-21 收修改稿.鲁文艳(1989 ), 女, 硕士研究生;E-mail: luwenyan_happy@163.com.

** 通信作者;E-mail: hpli@ niglas.ac.cn. 
Based on the comprehensive analysis of the economic contribution, generation of pollutants strength and governance efficiency of different industries and enterprises, the industry is divided into six categories. Each category was proposed with the optimization strategies for key development, encouraging development, or restricting development. Enterprises were divided into four types and the corresponding enterprise regulatory strategies were proposed for supporting, encouraging, or restricting the development, and even being gradually shut down. Classification and evaluation of industry and enterprises provide a reference for other regions, and also provide technical guidance to conduct the "water pollution prevention action plan".

Keywords: Industry pollution; enterprise; cluster analysis; optimization strategy; Lake Qiandao Basin

随着我国工业化进程不断加快, 工业废水和污染物排放量持续增加, 导致水污染问题日益严重, 逐渐成 为威胁经济可持续发展与人民生活健康的重大环境问题. 国家和地方政府对水环境保护非常关注, 先后实 施了污水排放许可申报和达标排放的管理制度和针对工业点源污染实施 “零点行动”, 但由于工业规模的不 断扩张和污染排放基数大幅度增加, 水环境仍然呈现出持续恶化的趋势. 近年来, 为进一步改善环境, 提升 可持续发展的能力, 我国以改变发展方式、注重发展质量和效率以及促进产业结构转型升级作为解决环境 问题的重要途径. 2015 年出台的 “水污染防治行动计划” 明确提出, 要推动经济结构转型升级, 制定产业结 构调整指导目录及相关行业污染物排放标准, 淘汰落后生产工艺装备和产品, 尤其要狠抓工业污染防治, 取 缔“十小”企业, 全面排查装备水平低、环保设施差的小型工业企业. 当前亟需一套面向行业和企业的评价方 法, 落实水污染防治行动计划. 目前已有的研究普遍认为, 区域或流域产业结构与水环境密切相关 ${ }^{[1-4]}$, 产业 结构优化调整是实现污染物减排和提升发展潜力的重要途径 ${ }^{[5-6]}$, 产业结构优化的方向主要依据不同行业 和企业的污染排放强度、经济效益和社会效益 ${ }^{[7-9]}$. 2010 年国家在全国范围内对各类重点污染源进行系统的 普查, 建立健全了各级污染源信息数据库, 明确了工业点源的空间分布和排放特征 ${ }^{[10-13]}$, 识别出主要污染排 放行业, 为加强环境监管建立了良好的基础. 由于环境问题既是管理问题, 也是发展问题, 除加强企业的末 端管理外, 同时需要从区域发展的角度, 通过合理评价企业的污染排放、经济和社会发展贡献, 制定行业发 展指导目录引导产业结构的优化, 确定企业监管的方法, 提升区域发展的质量和效率. 目前针对千岛湖地区 水环境的研究已比较多, 主要集中于千岛湖湖体的水质变化方面 ${ }^{[14-16]}$, 或者对其水质与经济发展关系进行 分析 ${ }^{[17]}$, 但从水环境的工业行业污染结构与优化管理方面的研究还较为薄弱. 基于此, 本研究建立在第一 次污染普查及后续的更新数据, 重点针对千岛湖国家级战略水源地的水环境保护需求, 以千岛湖流域的淳 安县为研究区域, 采用多元统计方法, 从企业和行业两个层次对淳安县水环境污染排放与经济贡献进行综 合评价, 探讨工业行业污染结构和企业分类管理策略, 为落实 “水污染防治行动计划”, 加强千岛湖水环境保 护提供依据,也可为其它地区行业结构优化和企业水环境强化管理提供参考.

\section{1 研究区域}

千岛湖流域总面积约为 $10442 \mathrm{~km}^{2}$, 行政分区属于安徽省和浙江省. 本文研究区为千岛湖下游部分 (图 1 ), 即浙江省杭州市境内的淳安县, 其中流域内 $98 \%$ 的水域集中在淳安县境内, 其境内的千岛湖是浙江省和 杭州市最为重要的饮用水源保护地,2011 年底被国家发改委定位为 “国家战略水源地”, 列人国家良好湖库 保护的第一试点. 因千岛湖处于淳安县中心, 属于千岛湖湖泊水质响应的敏感范围, 周边的工业企业主要分 布于沿湖和沿河的地带, 人湖比例高. 作为全流域的汇水区, 上游新安江断面 $\mathrm{COD}_{\mathrm{Mn}}$ 约占流域的 $74 \%$, 下游 约占 $26 \%$, 但因下游地区处于千岛湖周边地区, 对水体有较大的影响. 目前淳安县一、二、三产业所占比重分 别为 $15.68 \% 、 39.71 \% 、 44.61 \%$, 第二产业尤其是工业在流域产业结构中占有较大的比重, 并且形成以纺织 业、饮料制造业以及电气机械及器材制造业为主的工业格局. 工业排放 $\mathrm{COD}_{\mathrm{Mn}}$ 占其排放总量的 $20 \%$ 以上, 对 水环境影响大.

\section{2 方法与数据}

\section{1 研究方法}

聚类分析是统计学上研究多要素事物分类问题的数量方法, 能够基于多变量的分析, 综合确定样本之 间的亲疏关系, 并据此对样本进行分类. 常见的聚类分析方法有系统聚类法、动态聚类法和模糊聚类法 


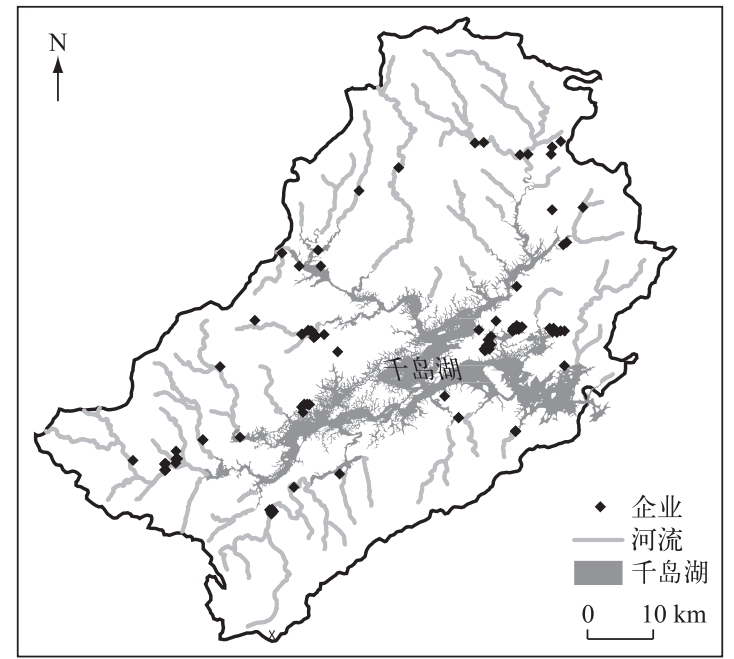

图 1 研究区及企业分布

Fig.1 Distribution of research area and enterprise

等 ${ }^{[18]}$. 本研究采用的系统聚类法中的 $Q$ 型聚类, 基本步骤为: 每个样本自成一类, 按照样本差异的测度方法 度量所有样本间的“亲疏程度”, 并将其中最接近的样本聚成一小类, 形成 $n-1$ 类; 重复上述过程, 不断将所 有个体和小类聚集成越来越大的类, 直到所有个体聚为一个最大类为止 ${ }^{[19]}$. 计算样本间的差异程度时采用 平方欧氏距离,其计算公式为:

$$
D_{i j}^{2}=\sum_{k=1}^{n}\left(X_{i k}-X_{j k}\right)^{2}
$$

式中, $D_{i j}^{2}$ 为平方欧式距离, 代表样本 $i$ 和样本 $j$ 之间的差异程度; $X_{i k}$ 代表第 $i$ 个样本在第 $k$ 个变量上的得分, $X_{j k}$ 代表第 $j$ 个样本在第 $k$ 个变量上的得分; $n$ 代表变量个数.

\section{2 评价指标选取}

为了综合分析各行业、企业经济贡献、污染产生量和排放量, 本研究选取各企业以及行业的工业总产 值、单位产值污染物产生量和污染排放率作为评价指标, 工业总产值可反映出企业或行业的经济贡献, 单位 产值污染产生量可以反映出污染产生强度, 而依据工业污染的处理状况, 采用排放和产生污染的比例来代 表污染治理效果. 本次污染排放指标采用工业企业普遍监测的 $\mathrm{COD}_{\mathrm{Mn}}$ 指标.

\section{3 数据描述}

所采用的污染产生量和排放量数据主要来自于淳安县 2010 年发布的第一次全国污染源普查数据, 并 剔除后续到 2013 年已经关闭的企业, 企业和工业行业总产值采用 2014 年的经济统计数据和淳安县统计年 鉴,包括工业企业名称、工业行业类别以及 $\mathrm{COD}_{\mathrm{Mn}}$ 产生量和排放量. 在企业选取方面, 从污染普查中的 500 家排污企业中选取出具有 $\mathrm{COD}_{\mathrm{Mn}}$ 污染排放的 180 家企业作为分析样本. 其中 180 家企业产值占 500 家企业 总产值的 $83.41 \%$, 占当年工业总产值的 49.27\%. 根据国民经济行业分类标准 ( GB/T 4754-2011), 将其划 分为采矿业、纺织业和饮料制造业等 19 个行业类型.

由于污染普查实施后只对关停企业和重点排污企业数据进行更新,而本文评价中所采用的企业污染排 放数据处于 2010-2013 年, 工业行业经济数据采用 2014 年的统计年鉴数据, 为了从企业污染排放的数据中 分类统计不同行业的贡献特点, 假设 2010-2014 年企业规模和技术进步方面无显著变化, 即企业单位产值 污染排放量基本一致. 


\section{3 结果分析}

\section{1 工业污染的行业结构}

3.1.1 工业行业结构状况 180 家企业的工业总产值达 68.65 亿元, 主要以纺织业、饮料制造业以及金属制品 业为主 (图 2), 这三类行业工业总产值占 180 家企业样本的 $77.48 \%$, 其余 16 个行业的工业总产值所占比重 低, 仅为 $22.52 \%$. 纺织业、饮料制造业以及金属制品业的经济贡献处于行业前列, 分别占工业总产值的 $31.68 \% 、 27.47 \% 、 18.33 \%$; 其次为化学原料及其制品业、电气机械及器材制造业、通用设备制造业以及食品 制造业; 其它行业的经济贡献均低于 $2 \%$.

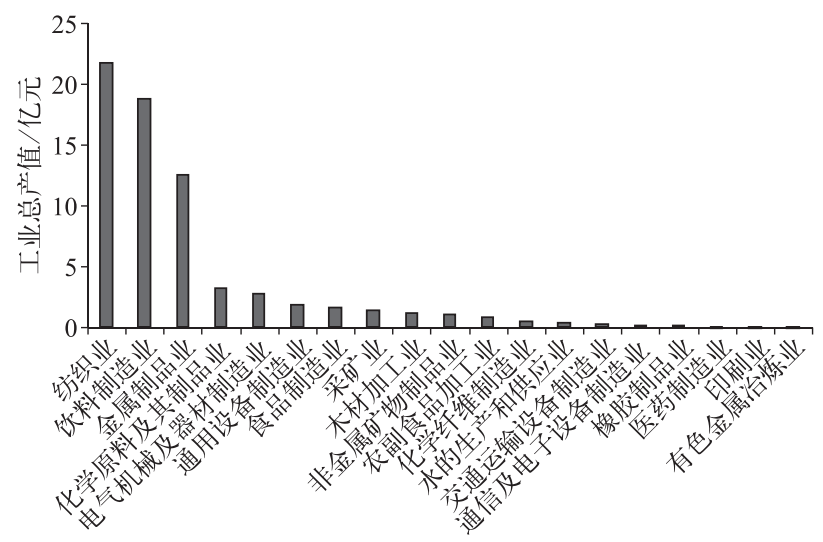

图 2 淳安县工业行业结构

Fig. 2 Industry structure of Chun'an County

3.1.2 工业行业污染贡献量 由 $\mathrm{COD}_{\mathrm{Mn}}$ 产生量可以看出, 淳安县饮料制造业和纺织业的污染贡献率位居行业 前列 (图 3), 分别占统计行业的 $42.53 \% 、 21.94 \%$; 其次为食品制造业、农副食品加工业、金属制品业、采矿业 以及化学原料及其制品业, 其 $\mathrm{COD}_{\mathrm{Mn}}$ 产生贡献率介于 $3 \% \sim 11 \%$ 之间; 其它行业的 $\mathrm{COD}_{\mathrm{Mn}}$ 产生量相对来说较 低, 其贡献率均低于 $2 \% . \mathrm{COD}_{\mathrm{Mn}}$ 产生量的行业差别,一方面与行业的生产工艺有关, 如纺织业、食品制造业、 农副食品加工业以及化学原料及其制品业, 这些行业的生产工艺水平低; 另一方面与其行业规模有关, 如饮 料制造业、纺织业以及金属制品业, 其行业产值均高于 10 亿元, 从而导致其 $\mathrm{COD}_{\mathrm{Mn}}$ 产生量处于高水平.

$\mathrm{COD}_{\mathrm{Mn}}$ 排放量方面, 以纺织业和饮料制造业表现最为突出, 其贡献率分别为 $40.16 \% 、 18.98 \%$; 其次为农 副食品加工业、食品制造业、化学原料及其制品业以及金属制品业, 其贡献率介于 $4 \% \sim 12 \%$ 之间; 水的生产 供应业、电气机械及器材制造业、木材加工业等行业的排放量很小, 其贡献率均低于 $3 \%$. 影响污染物排放量 的因素主要包括行业规模以及污染物治理水平. 其中纺织业和饮料制造业表现的最为明显,一方面受其行 业经济规模影响, 2 个行业污染物排放量大; 同时由于污染物处理水平的不同, $\mathrm{COD}_{\mathrm{Mn}}$ 排放量存在很大差异. 虽然纺织业 $\mathrm{COD}_{\mathrm{Mn}}$ 产生量低于饮料制造业, 但由于对 $\mathrm{COD}_{\mathrm{Mn}}$ 的处理力度低, 使得饮料制造业 $\mathrm{COD}_{\mathrm{Mn}}$ 排放贡献 率为纺织业的 2 倍多.

3.1.3 行业单位产值的污染产排水平 淳安县 $\mathrm{COD}_{\mathrm{Mn}}$ 产生强度和 $\mathrm{COD}_{\mathrm{Mn}}$ 排放强度表现出较大的差异性( 表 1). 单位产值 $\mathrm{COD}_{\mathrm{Mn}}$ 产生量以农副食品加工业( $34.78 \mathrm{~kg} /$ 万元)、食品制造业 (24.48 kg/万元) 位居前两位, 说明行业的产污水平高; 其次为采矿业、饮料制造业、水的生产和供应业、化学原料及其制品业、纺织业以及 通用设备制造业; 其它行业的 $\mathrm{COD}_{\mathrm{Mn}}$ 产生强度则比较低. 单位产值 $\mathrm{COD}_{\mathrm{Mn}}$ 排放量中农副食品加工业、水的生 产和供应业、食品制造业分别为 $13.21 、 7.01 、 5.42 \mathrm{~kg} /$ 万元, 处于行业前列; 其次为化学原料及其制品业、纺织 业、有色金属冶炼业、采矿业、橡胶制品业以及化学纤维制造业; 其它行业的 $\mathrm{COD}_{\mathrm{Mn}}$ 排放强度均处于较低水 平. 此外, 工业各行业中 $\mathrm{COD}_{\mathrm{Mn}}$ 产生强度和排放强度表现出高度一致性的为农副食品加工业, 主要受行业经 济规模小、 $\mathrm{COD}_{\mathrm{Mn}}$ 治理力度较小等影响. 


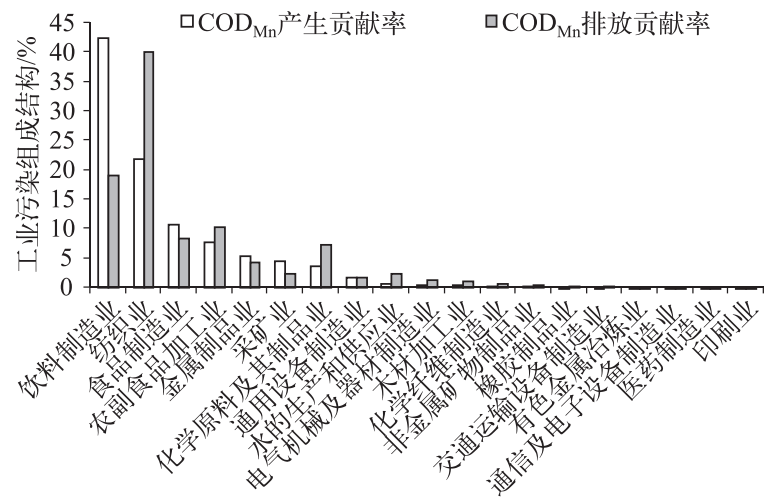

图 3 淳安县工业行业污染物组成结构

Fig.3 Pollutant composition structure of industry in Chun'an County

表 1 淳安县工业行业污染物产排水平

Tab.1 Industry pollution level in Chun'an County

\begin{tabular}{lcccc}
\hline 工业行业 & $\begin{array}{c}\text { 单位产值 } \mathrm{COD}_{\mathrm{Mn}} \\
\text { 产生量/ }(\mathrm{kg} / \text { 万元 })\end{array}$ & $\begin{array}{c}\text { 单位产值 } \mathrm{COD}_{\mathrm{Mn}} \\
\text { 排放量/ }(\mathrm{kg} / \text { 万元 })\end{array}$ & $\begin{array}{c}\text { 经济贡献率/ } \\
\%\end{array}$ & $\begin{array}{c}\mathrm{COD}_{\mathrm{Mn}} \text { 排放率/ } \\
\%\end{array}$ \\
\hline 农副食品加工业 & 34.78 & 13.21 & 1.19 & 37.97 \\
食品制造业 & 24.48 & 5.42 & 2.34 & 22.13 \\
采矿业 & 11.96 & 1.84 & 1.99 & 15.38 \\
饮料制造业 & 8.29 & 1.05 & 27.47 & 12.69 \\
水的生产和供应业 & 7.00 & 7.01 & 0.52 & 100.00 \\
化学原料及其制品业 & 4.11 & 2.38 & 4.71 & 57.94 \\
纺织业 & 3.70 & 1.93 & 31.68 & 26.74 \\
通用设备制造业 & 3.61 & 0.97 & 2.66 & 100.00 \\
有色金属冶炼业 & 1.85 & 1.85 & 0.04 & 100.00 \\
橡胶制品业 & 1.83 & 1.83 & 0.19 & 22.94 \\
金属制品业 & 1.58 & 0.36 & 18.33 & 100.00 \\
化学纤维制造业 & 1.27 & 1.27 & 0.67 & 100.00 \\
木材加工业 & 0.98 & 0.99 & 1.77 & 100.00 \\
交通运输设备制造业 & 0.87 & 0.87 & 0.40 & 97.89 \\
非金属矿物制品业 & 0.52 & 0.51 & 1.59 & 100.00 \\
电气机械及器材制造业 & 0.44 & 0.45 & 4.08 & 100.00 \\
医药制造业 & 0.20 & 0.20 & 0.09 & 6.25 \\
通信及电子设备制造业 & 0.11 & 0.01 & 0.22 & 100.00 \\
印刷业 & 0.02 & 0.02 & 0.07 & \\
\hline
\end{tabular}

\section{2 工业行业聚类分析}

综合考虑行业经济贡献、行业产污水平和治理条件,将工业行业划分为 6 类(图 4).

第 I 类行业包括饮料制造业和金属制品业,该类型行业经济贡献高、 $\mathrm{COD}_{\mathrm{Mn}}$ 产生强度处于中等或较低水 平, 受行业规模影响污染物产生总量较大, 由于污染物治理效果好, $\mathrm{COD}_{\mathrm{Mn}}$ 排放量大大降低; 第 II 类行业仅有 纺织业, 该行业经济贡献最高, $\mathrm{COD}_{\mathrm{Mn}}$ 产生强度处于中等水平,污染物产生量仅次于饮料制造业, 但由于污染 物的治理效果差, $\mathrm{COD}_{\mathrm{Mn}}$ 排放量为行业最高, 高污染特点明显; 第 III 类行业即化学原料及其制品业, 该行业经 济贡献中等、 $\mathrm{COD}_{\mathrm{Mn}}$ 产生量和排放量均处于较高水平, 污染治理效率也低; 第 IV 类行业包括采矿业、通信及电 子设备制造业和通用设备制造业, 该类型行业的经济贡献率中等, 除采矿业外 $\mathrm{COD}_{\mathrm{Mn}}$ 产生强度也低, 且污染 
物的治理效果好,大大降低了行业的 $\mathrm{COD}_{\mathrm{Mn}}$ 排放量; 第 $\mathrm{V}$ 类行业包括农副食品加工业和食品制造业,该类型 行业表现为典型的经济贡献低、COD ${ }_{\mathrm{Mn}}$ 产生强度极高的特点, 虽然污染物的治理效果较好, 但其排放量仍然 很高; 第VI类行业包括水的生产和供应业、电气机械及器材制造业、非金属矿物制品业、木材加工业、医药制 造业、印刷业、交通运输设备制造业、化学纤维制造业、有色金属冶炼业以及橡胶制品业, 该类型行业的经济 贡献率低、 $\mathrm{COD}_{\mathrm{Mn}}$ 产生强度也低、污染物治理效率低, 由于行业规模比较小, $\mathrm{COD}_{\mathrm{Mn}}$ 排放量总体较低.

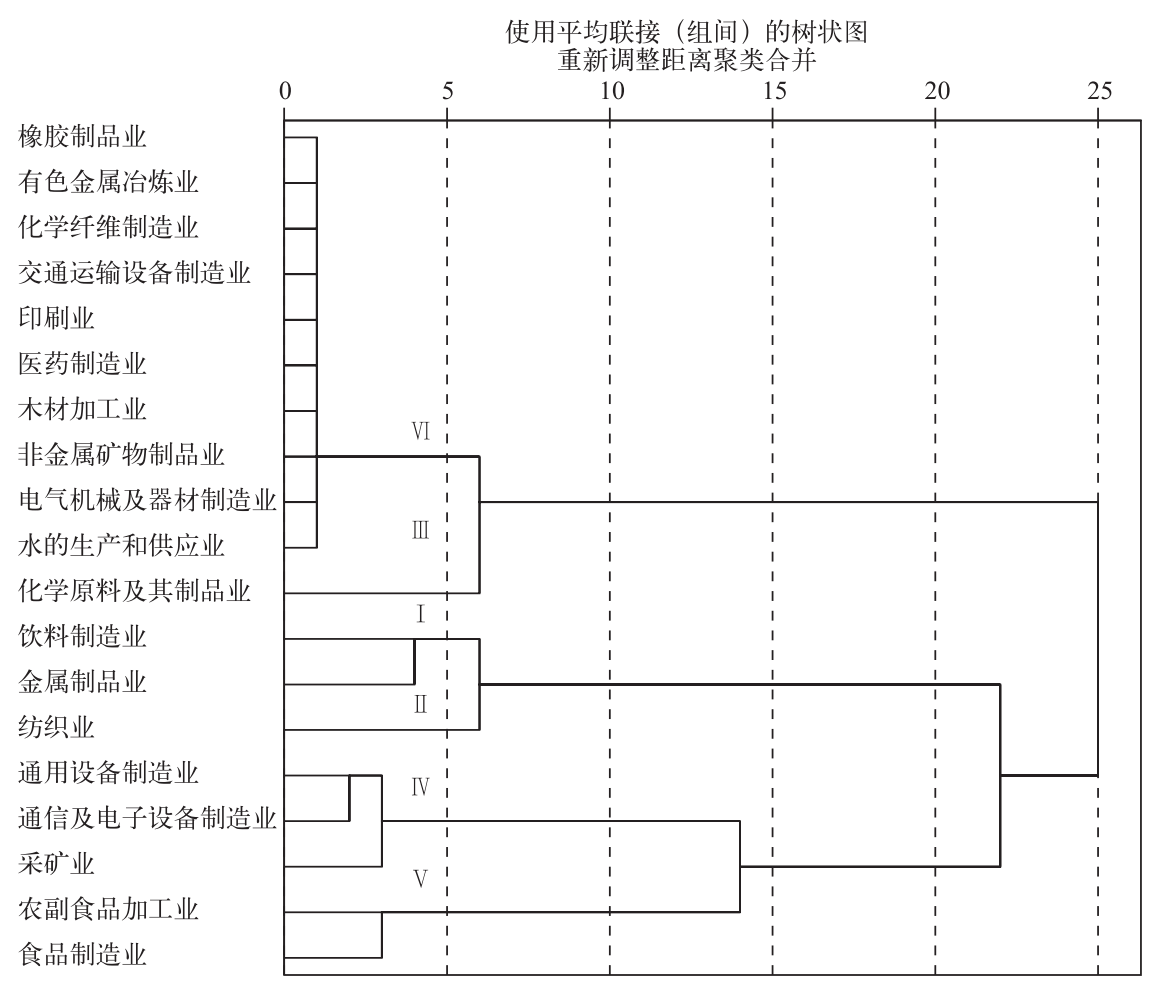

图 4 工业行业聚类树状图

Fig.4 Industry clustering tree

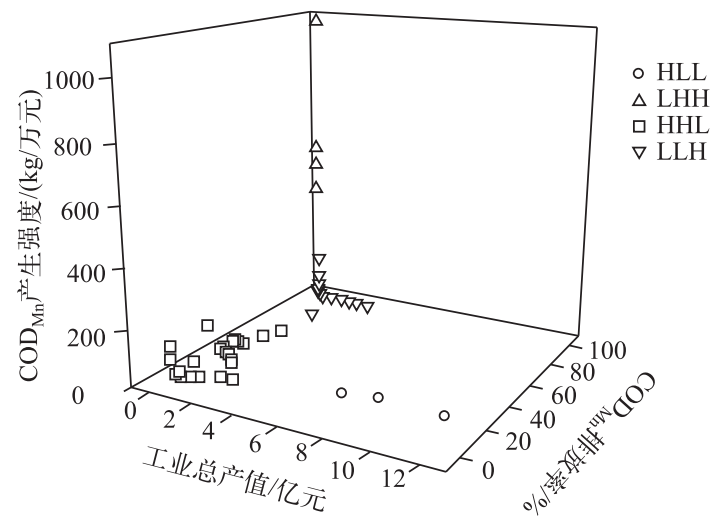

图 5 工业企业类型划分结果

Fig.5 Classification results of industrial enterprises

\section{3 工业企业聚类分析}

不同行业内部因企业规模、生产工艺、原料产 品、企业位置等方面的差异, 在经济贡献、污染产生 和污染治理水平方面也有较大的差异, 仅仅通过行 业管理并不能达到优化发展和强化管理的目的, 需 要对企业进行综合评价. 企业作为污染排放的微观 主体, 从企业角度分析能够更好地补充行业分析的 缺失, 为工业污染源的治理以及工业结构调整提供 更为科学的决策依据. 据此将淳安县 180 家企业采 用聚类分析的方法进行综合划分, 可分为差异明显 的 4 种类型 (图 5).

高经济贡献、低产污强度、低污染排放率 (HLL). 该类型主要包括 3 家企业, 工业总产值高, 均为淳安县的龙头企业; $\mathrm{COD}_{\mathrm{Mn}}$ 产生强度较低, 清 洁生产水平较高, 较大的经济规模使其污染物产生 
量大; 污染物治理效果好, 污染排放强度低,对水环境的影响相对来说较小,该类型企业的环境经济性最优.

高经济贡献、较高产污强度、低污染排放率 (HHL). 该类型主要有 36 家企业, 工业总产值高、COD ${ }_{\mathrm{Mn}}$ 产 生强度较高,污染物治理效果好,大大降低其污染物排放量,减轻了对水环境的压力.

低经济贡献、低产污强度、高污染排放率 (LLH). 该类型企业数量大, 共涉及 132 家企业, 并且以中小型 经济规模为主, 是当前淳安县经济发展的重要推动力; $\mathrm{COD}_{\mathrm{Mn}}$ 产生强度低, 清洁生产水平高; 受其经济规模影 响, $\mathrm{COD}_{\mathrm{Mn}}$ 产生量和排放量都处于低水平, 污染物均未经有效处理直接排放进人水环境.

低经济贡献、高产污强度、高污染排放率 ( $\mathrm{LHH}$ ) 。该类型共有 9 家企业, 工业总产值低, $\mathrm{COD}_{\mathrm{Mn}}$ 产生强度 高, 企业清洁生产水平低. 由于污染物均直接进人水环境, 使其污染物排放强度也处于高水平, 对水环境压 力大,属于典型的“十小”企业,同时该类型企业均属于农副食品加工业.

\section{4 讨论}

\section{1 工业污染行业组成结构及优化策略}

区域产业结构作为人类经济活动影响生态环境方式的集中体现, 它是环境资源消耗和污染物产生种类 及数量的 “控制体” ${ }^{[20]}$, 因此在工业发展计划和管理中若能依据污染产排放特点引导产业结构不断优化, 可 以在很大程度上减轻其对水环境的压力. 目前淳安县传统的支柱产业主要为纺织业、饮料制造业和金属制 品业, 而单位产值污染产生量较大的行业依次为农副食品加工业、食品制造业、采矿业、饮料制造业. 如果不 考虑各年在污染治理方面的进步, 淳安县 1980 年以来工业单位产值的 $\mathrm{COD}_{\mathrm{Mn}}$ 平均产生量由 $7.50 \mathrm{~kg}$ 万万元下 降到目前的 $4.98 \mathrm{~kg}$ /万元, 其工业结构不断优化. 但从目前的工业行业结构及其污染排放结构来看, 淳安县 工业污染还存在结构性问题, 纺织业、饮料制造业、化学原料及其制品业、食品制造业以及农副食品加工业 为 $\mathrm{COD}_{\mathrm{Mn}}$ 产生的主要行业, 其 $\mathrm{COD}_{\mathrm{Mn}}$ 产生量占总产生量的 $82.90 \%$, 其中食品制造和副食品加工的 $\mathrm{COD}_{\mathrm{Mn}}$ 产 生和排放量均远超过其经济贡献, 纺织业作为传统的支柱产业还存在污染治理力度不够的问题; 化学原料 及其制品业作为污染产生量高和治理力度不够的行业还占有较高的比例.

工业作为重要的污染源, 目前在污染源解析方面已取得大量研究成果 ${ }^{[4,10-14]}$, 为工业结构调整提供了基 础. 工业结构的调整则立足环境保护角度综合考虑经济、环境影响,提出具体的应对策略 ${ }^{[7-8]}$. 千岛湖独特的 水源地地位使其更加注重水环境保护, 工业行业的分类评价可为“水污染防治行动计划” 中确定淳安县产业 结构调整指导目录和落后产能淘汰方案制定提供科学指导. 因此, 在工业分类体系中, 对于饮料制造业、金 属制品业和纺织业三个传统支柱行业, 考虑到淳安县桑蜚养殖和优质水资源是其主要资源优势, 这三类仍 然为重点发展的行业, 目前和今后发展中尤其要注重纺织业污染治理力度的提升、饮料业改善工艺减少污 染产生量, 因规模大、污染排放基数大, 还需要注意行业发展布局与水环境容量相适应. 重点限制发展的行 业为第亚类的化学原料及化学品制造业和第 $\mathrm{V}$ 类的农副食品加工业和食品制造业, 这些行业污染产生量 高, 即使强化治理仍然有较大的排放量, 其次是采矿业, 也存在污染产生强度大的问题, 此外还影响到流域 的水源涵养能力, 对这些行业应该列人产业结构调整目录, 依法淘汰高污染的产能行业, 同时对新发展的行 业要设置严格的环境准人门槛. 第 $\mathrm{IV}$ 类的通信及电子设备制造业和通用设备制造业为鼓励发展的行业, 目 前 $\mathrm{COD}_{\mathrm{Mn}}$ 产生强度低, 污染治理也比较成功. 第 VI 类的水的生产和供应业、电气机械及器材制造业、交通运 输设备制造业、医药制造业等目前普遍存在污染直排的问题, 需要在加强监管的条件下进一步发展.

\section{2 工业企业发展的监管策略}

行业结构的优化调整已成为实现水环境保护的一种重要手段, 并且进行了相关实证研究 ${ }^{[7-8]}$, 但企业作 为污染排放的主体, 目前针对其管理与控制方面的研究几乎很少涉及. 而立足于企业确定其监管策略, 更有 利于从源头实现污染控制.

企业的综合分类中, HLL 型企业均属于行业分类的 I 类, 为淳安县龙头企业, 充分利用了淳安县的资源 优势, 主要位于千岛湖镇, 其污染基本得到较好的治理, 应该进一步做大做强, 重点支持其发展. HHL 型企业 具有较高的产值贡献, 同时也具有较高的污染产生量, 污染排放的强度相对较低, 企业分属于行业分类的 I $\mathrm{V}$ 类, 应以工艺改造和废水深度处理为主, 并且在一定程度上限制其发展. LLH 型企业产值较低, 但数量达 到 132 家, 分布面积广, 为解决淳安县的就业发挥着重要作用, 这些企业因污染排放监管不利, 有些甚至以 
直排为主, 因此在今后发展中应以整改为主. LHH 型企业均属于第 $\mathrm{V}$ 类限制发展的行业, 同时考虑其低产 值贡献以及高排污强度特点, 应以逐渐关停为主.

\section{5 结论}

1) 本文明确了千岛湖流域下游的淳安县的工业行业结构、行业产值贡献和污染排放水平. 在 19 个工业 行业中,从产值来看工业行业以纺织业、饮料制造业和金属制品业为支柱产业. 行业单位产值 $\mathrm{COD}_{\mathrm{Mn}}$ 排放量 以农副食品加工业 (34.78 kg/万元)、食品制造业(24.48 kg/万元) 位居前两位, 其次是采矿业、饮料制造业、 水的生产和供应业、化学原料及其制品业、纺织业以及通用设备制造业. 从 $\mathrm{COD}_{\mathrm{Mn}}$ 排放总量来看, 饮料制造 业和纺织业的污染贡献率最高, 其次为食品制造业、农副食品加工业、金属制品业、采矿业以及化学原料及 其制品业.

2) 淳安县 1980 年以来行业结构不断优化, 但现状行业结构还存在结构性污染问题. 目前饮料制造业、 金属制品业和纺织业三个传统支柱行业应重点发展,但在行业布局时要注重污染排放总量与所在区域环境 容量相协调, 尤其要通过工艺改造和废水深度处理减少纺织业污染排放; 第 III 类的化学原料及其制品业和 第 $\mathrm{V}$ 类的农副食品加工业和食品制造业应提高环境准人门槛, 限制其发展. 第 $\mathrm{I}$ 类的通信及电子设备制造 业和通用设备制造业是未来鼓励发展的行业. 第 VI 类的水的生产和供应业、电气机械及器材制造业、交通 运输设备制造业、医药制造业等目前普遍存在污染直排的问题, 需要进一步加强监管.

3)行业和企业的分类有助于贯彻实施“水污染防治行动”, 企业综合分类中 HLL 型企业为龙头企业, 要 重点支持; HHL 型企业在工业产值上有较高的贡献, 在鼓励发展时要注重废水深度处理和设置严格的 $\mathrm{COD}_{\mathrm{Mn}}$ 排放限值, 尤其要加强行业 III 类和 V 类中 HHL 型企业的限制; LLH 型企业具有良好的发展前景,应 以整改为主; LHH 型企业应该以逐渐关停为主.

\section{6 参考文献}

[ 1 ] Peng Yahui, Zhou Keping. Case study on evolution of industry structure and the response of water environment of Dongjiang Lake Basin. Acta Agriculturae Universitatis Jiangxiensis, 2014, 36(5) :1152-1158. [ 彭亚辉, 周科平. 东江流 域产业结构变迁与水环境响应研究. 江西农业大学学报, 2014, 36(5): 1152-1158.]

[ 2 ] Wang Lei, Zhang Lei, Duan Xuejun et al. Water-environment effects of industry structure in Taihu Lake Basin in Jiangsu Province. Acta Ecologica Sinica, 2011, 31(22): 6832-6844. [王否, 张否, 段学军等. 江苏省太湖流域产业结构的 水环境污染效应. 生态学报, $2011,31(22)$ : 6832-6844.]

[ 3 ] Zhao Xiaofeng, Huang Xianjin. Response of water environment to industrial structure evolvement: A case in Shedu River Basin. Environmental Pollution and Control, 2010, 32(1): 9-13. [赵小风, 黄贤金. 产业结构演变的流域水环境响 应研究: 以社渎港流域为例. 环境污染与防治, 2010, 32(1) : 9-13.]

[ 4 ] Lu Yingying, Zhang Ming, Huang Guanzhong. Analysis of industrial structural pollution characteristic and control countermeasures in the Taihu Lake Basin in Zhejiang Priovince. Environmental Pollution and Control, 2011, 31(6) : 86-89, 96. [ 卢瑛芗, 张明, 黄冠中. 浙江省太湖流域工业结构性污染特征分析与调控对策. 环境污染与防治, 2011, 31(6): 86-89, 96.]

[ 5 ] Wang Xun, Zhang Weijie. The regional differences of industrial pollution and environmental regulation, the industrial structure in China, based on the Eastern, Central and Western Panel Data Empirical Research. Research on Financial and Economic Issues, 2011, 11: 23-30. [王询, 张为杰. 环境规制、产业结构与中国工业污染的区域差异一一基于东、 中、西部 Panel Data 的经验研究. 财经问题研究, 2011, 11:23-30.]

[6] Li Mingsheng, Zhou Lei, Chen Yuanhang et al. Effect of economic structure adjustment on pollution emission: A case study of COD. Environmental Science, 2014, 35(8): 3212-3218. [李名升, 周否, 陈远航等. 经济结构调整的污染减 排效应: 以 COD 减排为例. 环境科学, $2014,35(8)$ : 3212-3218. ]

[ 7 ] Wang Xiqin, Yang Zhifeng, Liu Changming. Regional economic structural adjustment and water environmental protection: A case of Guanzhong Region in Shanxi Province. Acta Geographica Sinica, 2000, 55(6) : 707-718. [王西琴, 杨志峰, 刘昌明. 区域经济结构调整与水环境保护以陕西关中地区为例. 地理学报, 2000, 55(6): 707-718.]

[ 8 ] Zhou Shuchun, Chen Bei, Liao Fei et al. Water environment and industrial structure optimization model in a small town of 
Three Gorges-A case study in Fenshui of Wanzhou. Environmental Science and Management, 2007, 32(6): 73-78. [ 周 淑春, 陈蓓, 廖飞等. 三峡库区小城镇水环境与工业产业结构优化模型一一万州区分水镇为例. 环境科学与管 理, 2007, 32(6): 73-78.]

[ 9 ] Xia Xunfeng, Gu Yu, Xi Beidou et al. Research on agricultural structure regulation in Fuxian Lake Basin based on water environment constraints. Research of Environmental Sciences, 2010, 23(10) : 1274-1278. [夏训峰, 顾雨, 席北斗等. 基 于水环境约束的抚仙湖流域农业结构调整研究. 环境科学研究, 2010, 23(10): 1274-1278.]

[10] Lei Pei, Zhang Hong, Shan Baoqing et al. Analysis of COD and $\mathrm{NH}_{3}-\mathrm{N}$ discharge from industrial pollution source of Danjiangkou Reservoir area and upper reaches. Resources and Environment in the Yangtze Basin, 2014, 23(2) : 243-251. [ 雷 沛, 张洪, 单保庆等. 丹江口库区及上游 COD 和氨氮工业污染源解析. 长江流域资源与环境, 2014, 23(2) : 243-251.]

[11] Zeng Zhixiang, Zhang Hong, Shan Baoqing et al. Analysis of industrial pollution sources of the middle and lower reaches of Hanjiang River Basin. Resources and Environment in the Yangtze Basin, 2014, 23(2) : 252-259. [曾祉祥, 张洪, 单保 庆等. 汉江中下游流域工业污染源解析. 长江流域资源与环境, 2014, 23(2): 252-259.]

[12] Jiang Haibing, Xu Jiangang. Spatial distribution feature of industrial point source in Jiangsu Huai River Basin. Resources and Environment in the Yangtze Basin, 2013, 22(6) : 742-749. [蒋海兵, 徐建刚. 江苏淮河流域工业点源负荷空间 分布特征研究. 长江流域资源与环境, 2013, 22(6): 742-749.]

[13] Yan Runrun, Chao Jianying, Zhang Lei et al. Research on the load of industrial pollution in the Taihu Lake Basin in Jiangsu Province. China Rural Water and Hydropower, 2012, (3) : 39-43. [颜润润, 晁建颖, 张否等. 太湖流域江苏片区 工业源污染负荷研究. 中国农村水利水电, 2012, (3) : 39-43.]

[14] Li Peipei, Shi Wen, Liu Qigen et al. Spatial and temporal distribution patterns of chlorophyll-a and the correlation analysis with environmental factors in Lake Qiandao. J Lake Sci, 2011, 23(4) : 568-574. DOI: 10.18307/2011.0412. [李培培, 史文, 刘其根. 千岛湖叶绿素 a 的时空分布及其与影响因子的相关分析. 湖泊科学, 2011, 23(4) : 568-574.]

[15] Yu Yuanlong, Ren Liping, Liu Qigen et al. Temporal and spatial distribution of nutrients and the influence factors of Lake Qiandao during 2007-2008. J Lake Sci, 2010, 22(5) : 684-692. DOI: 10.18307/2010.0509. [余员龙, 任丽萍, 刘其 根等. 2007-2008 年千岛湖营养盐时空分布及其影响因素. 湖泊科学, 2010, 22(5) : 684-692.]

[ 16] Han Xiaoxia, Zhu Guangwei, Wu Zhixu et al. Spatial-temporal variations of water quality parameters in Xin'anjiang Reservoir(Lake Qiandao) and the water protection strategy. J Lake Sci, 2013, 25(6) : 836-845. DOI: 10.18307/2013.0607. [ 韩晓霞, 朱广伟, 吴志旭等. 新安江水库 (千岛湖) 水质时空变化特征及保护策略. 湖泊科学, 2013, 25(6): 836-845.]

[17] Zhang Shanshan, Zhang Luocheng, Li Gang et al. Coordination analysis between water quality and economic development in Lake Qiandao Basin. J Lake Sci, 2014, 26(6) : 948-954. DOI : 10.18307/2014.0618. [张姗姗, 张落成, 李刚等. 千岛湖流域水质变化与经济发展耦合协调性分析. 湖泊科学, 2014, 26(6) : 948-954.]

[18] Xu Jianhua ed. Mathematical methods in modern geography. Beijing: Higher Education Press, 2002: 69-84. [徐建华. 现 代地理学中的数学方法. 北京: 高等教育出版社, 2002: 69-84.]

[19] Huang Jinchuan, Chen Shouqiang. Classification of China's urban agglomerations. Progress in Geography, 2015, 34(3) : 290-301. [黄金川, 陈守强. 中国城市群等级类型综合划分. 地理科学进展, 2015, 34(3) : 290-301.]

[20] Zhao Jun ed. Water environment and industrial structure optimization in Liaohe River Basin. Beijing: China Environmental Science Press, 2011：87. [赵军. 辽河流域水环境与产业结构优化. 北京: 中国环境科学出版社, 2011: 87.] 